\title{
Hepatite aguda criptogênica: uma entidade heterogênea com possibilidades de complicações
}

\section{Acute cryptogenic hepatitis: a heterogeneous entity, with possible complications}

Liana Codes'; Maria Isabel Schinoni'; Luiz Antonio Rodrigues Freitas²; Carlos Eduardo Rolim³; Ludmilla Matos ${ }^{3}$; Luciana Matteoni ${ }^{3}$; Zilton Andrade ${ }^{2}$; Raymundo Paraná ${ }^{4}$

\begin{tabular}{l|l}
\multicolumn{1}{c|}{ Unitermos } & resUmo \\
Criptogênica & $\begin{array}{l}\text { Hepatites agudas ou crônicas de causas não definidas constituem um problema na prática de médicos clíni- } \\
\text { cos e gastroenterologistas. Apesar do desenvolvimento de sofisticados testes laboratoriais, uma proporção } \\
\text { Aguda }\end{array}$ \\
Crônica & $\begin{array}{l}\text { gênificas ou hepatites não A-E. Possíveis etiologias são sugeridas: vírus desconhecido, doenças metabólicas ou } \\
\text { hepatite auto-imune de apresentação atípica. Recentemente, nosso grupo demonstrou que, num centro de } \\
\text { Hepatite }\end{array}$ \\
$\begin{array}{l}\text { referência no Brasil, 17\% dos casos de hepatites agudas são criptogênicos, com alguns aspectos sugerindo } \\
\text { etiologia viral. Nós relatamos quatro casos de hepatite aguda criptogênica, demonstrando a heterogeneidade } \\
\text { dessa condição clínica associada à possibilidade de complicações, o que justifica uma criteriosa investigação } \\
\text { epidemiológica, clínica e laboratorial, assim como o acompanhamento desses pacientes. }\end{array}$
\end{tabular}

abstract

Acute or chronic hepatitis with no defined causes constitute a problem for clinical and gastroenterologists. In spite of sophisticated tests, a substantial proportion of hepatitis remains with no certain cause. They are cryptogenic hepatitis or hepatitis no A-E. Possible aetiologies are suggested: unknown virus, metabolic diseases or auto-immune hepatitis with atypical presentation. Recently, our group demonstrated that, in a reference center for hepatic diseases in Brazil, 17\% of cases of acute hepatitis are cryptogenic, with some aspects suggesting viral aetiology. We described four clinical cases of acute cryptogenic hepatitis, demonstrating the heterogeneity of this condition that may be associated with possible complications. This justifies a careful epidemiological and laboratorial investigation, as well as a follow-up of those patients. key words

Cryptogenic

Acute

Chronic

Hepatitis

\section{Introdução}

Hepatites criptogênicas ou hepatites não A-E constituem um problema na prática de médicos clínicos. Apesar do desenvolvimento de sofisticados testes laboratoriais, uma proporção significativa das hepatites ainda permanece com causa não determinada.
Possíveis etiologias são sugeridas: vírus desconhecido ou hepatite auto-imune atípica. Recentemente, nosso grupo demonstrou que, num centro de referência brasileiiro, $17 \%$ dos casos de hepatites agudas são criptogênicos, com alguns aspectos lembrando etiologia viral: sintomas prodrômicos (febre, exantema, mialgia),

1. Mestra em Medicina Interna; aluna do curso de doutorado da Faculdade de Medicina da Universidade Federal da Bahia (FM/UFBA)

2. Professor do Departamento de Anatomia Patológica e Medicina Legal da UFBA; pesquisador do Centro de Pesquisa Conçalo Muniz, Fundação Oswaldo Cruz (FIOCRUZ-Bahia).

3. Estudante de Medicina da UFBA.

4. Livre-docente; doutor; mestre em Medicina; professor-adjunto do Departamento de Medicina da FM/UFBA.

Trabalho realizado no curso de pós-graduação em Medicina e Saúde da UFBA e no Centro de Pesquisa Conçalo Muniz, FIOCRUZ, apresentado no XVIII Congresso Brasileiro de Hepatologia (Campos do Jordão, outubro 2005). 
achados histológicos na fase aguda (necrose extensa, infiltrado mononuclear e corpos apoptóticos), resolução espontânea na maioria dos casos e cronificação em $20 \%{ }^{(9)}$. Na ultima década, novos vírus foram investigados, como os vírus $G$, TTV e SEN-V, mas o papel patogênico desses agentes não ficou documentado ${ }^{(5,8,13)}$. Alguns autores demonstraram semelhanças nas manifestações clínicas entre as hepatites auto-imune e criptogênica, sugerindo que essa última possa corresponder a uma doença de natureza auto-imune que não tenha sido diagnosticada por métodos sorológicos convencionais ${ }^{(4)}$. Outros trabalhos propuseram que a esteato-hepatite não alcoólica (NASH) seja uma das etiologias para hepatite crônica criptogênica ${ }^{(11)}$.

Nós relatamos quatro casos de hepatite aguda criptogênica, demonstrando a heterogeneidade dessa condição, que é associada à possibilidade de complicações, o que justifica uma criteriosa investigação epidemiológica, clínica e laboratorial.

\section{Caso 1}

Mulher de 43 anos apresentou dor abdominal e alteração de enzimas hepáticas (aspartato aminotransferase [AST] quatro vezes e alanina aminotransferase [ALT] cinco vezes acima do limite normal). Em 30 dias evoluiu com icterícia e piora laboratorial (AST 13 vezes e ALT 11 vezes acima do valor normal, com tempo de protrombina [TP], albumina e globulinas normais). A paciente negou passado de hemotransfusões, uso de drogas intravenosas, alcoolismo, medicamentos, fitoterápicos ou chás nos últimos seis meses. Marcadores virais (imunoglobulina da classe $\mathrm{M} /$ vírus da hepatite $\mathrm{A}$ [IgM-VHA], antígeno de superfície do vírus da hepatite $B[\mathrm{AgHBs}]$, IgM e imunoglobulina da classe $\mathrm{G} /$ antivírus da hepatite $\mathrm{B}$ [lgG-anti-HBc], antivírus da hepatite $C$ [anti-VHC], antivírus da hepatite $\mathrm{E}$ [anti-VHE], anticitomegalovírus [anti-CMV], VHC-RNA e DNA-VHB) e auto-anticorpos (fator antinuclear [FAN], antimúsculo liso, anti-liver kidney microsome [anti-LKM], anti-soluble liver antigen [anti-SLA] e antimitocôndria) foram negativos.

Em nova avaliação, o antimúsculo liso estava positivo (1/80, padrão vaso) e as enzimas hepáticas mantinham-se alteradas: AST 759UI/I (referência abaixo de 32UI/I) e ALT 487UI/I (referência abaixo de 52UI/l), sendo indicada uma biópsia hepática, a qual revelou hepatite com necrose submaciça e com aspectos de hepatite aguda viral prolongada.

Quatro meses depois havia persistência das alterações enzimáticas (AST e ALT três vezes o limite da normalidade) e antimúsculo liso positivo (1/160, padrão glomérulo), optando-se pela realização de uma segunda biópsia hepática, a qual revelou fibrose portal e septal isolando nódulos regenerativos. Nos espaços porta, presença de moderado edema e infiltrado mononuclear que invadia o parênquima. Viam-se discreto foco de necrose hepatocelular e apoptose, chamando a atenção intensa esteatose (Figuras 1, 2 e 3). Diante do quadro clínico evolutivo, iniciou-se o tratamento

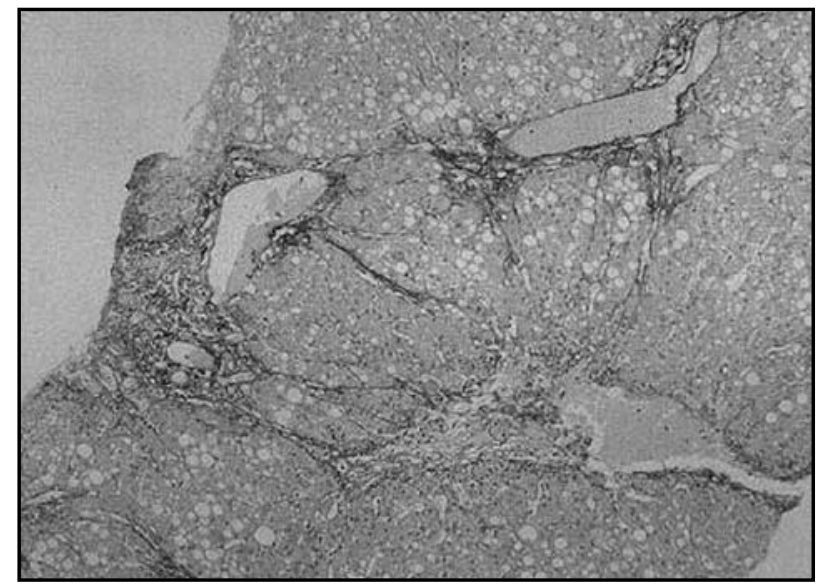

Figura 1 - Fibrose conectando alguns pequenos espaços porta e delimitando esboços de nódulos hepatocitários ( $H \& E, 100 X)$

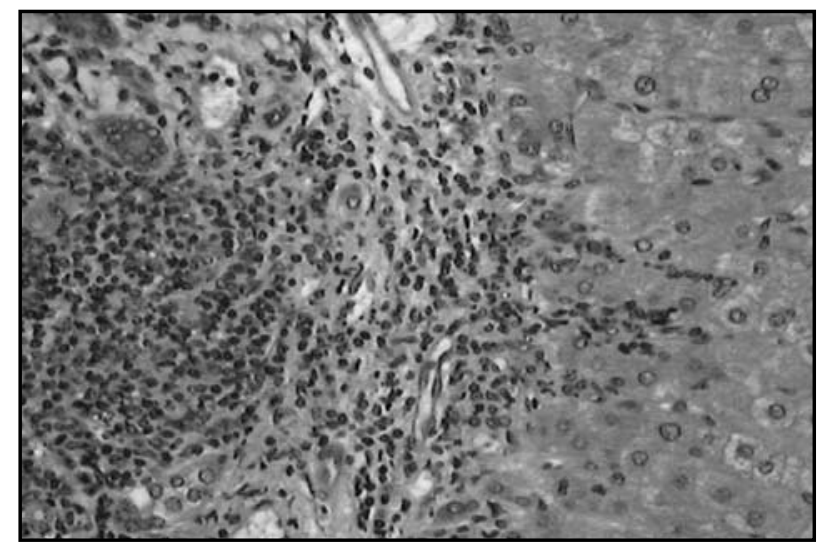

Figura 2 - Infiltração leucocitária mononuclear em um espaço porta ampliado. O infiltrado ultrapassa os limites estroma-parênquima, com coleções de células inflamatórias circunscrevendo grupos de hepatócitos (H\& E, 200X)

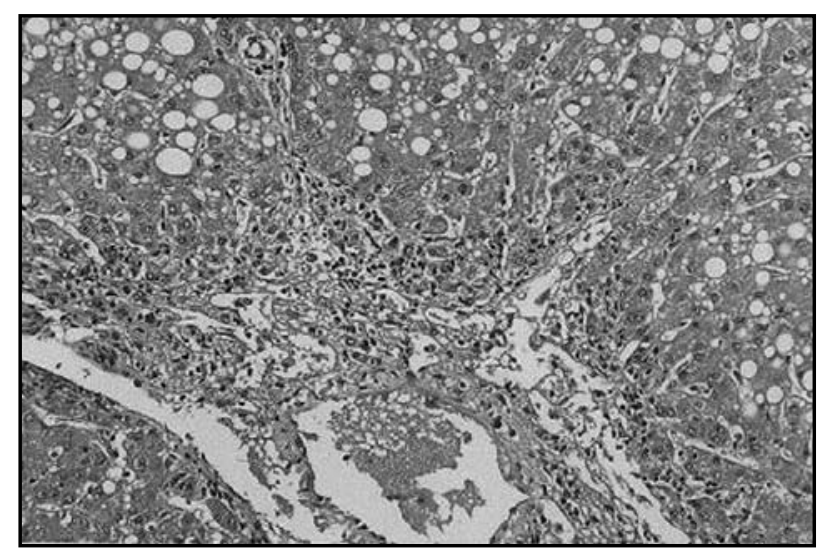

Figura 3 - Hepatócitos exibem esteatose de predominância macro-vacuolar, enquanto o tecido fibroso do espaço porta se mostra infiltrado por leucócitos mononucleares ( $H \& E, 200 X)$ 
empírico com prednisona ( $1 \mathrm{mg} / \mathrm{kg} / \mathrm{dia})$. Antes do início do tratamento, a paciente apresentava 15 pontos no score de hepatite auto-imune (sexo feminino, antimúsculo liso $>1: 80$, marcadores virais negativos, ausência de uso de drogas hepatotóxicas ou álcool, presença de hepatite de interface), sugerindo diagnóstico provável de hepatite auto-imune ${ }^{(7)}$. Em 15 dias de tratamento observou-se normalização das transaminases. Após sete meses, a paciente apresentava-se assintomática, com o perfil hepático normal e o antimúsculo liso negativado.

\section{Caso 2}

Paciente 48 anos, sexo feminino, apresentou fadiga e icterícia, sendo internada em outro hospital, de onde recebeu alta sem definição diagnóstica. Começou acompanhamento em nosso serviço em setembro de 2000 (Figuras 4 e 5). Não havia história de transfusão de sangue ou derivados, uso de chás, medicamentos ou álcool. Fez investigação diagnóstica com auto-anticorpos (FAN, antimúsculo liso, anti-LKM, antimitocôndria e anti-SLA), marcadores virais (vírus $B$ e $C$, incluindo RNA-VHC e DNA-VHB), ferritina, coeficiente de saturação de transferrina, ceruloplasmina, cobre sérico e urinário em duas ocasiões, com seis meses de intervalo, sendo todos os resultados negativos. A ultra-sonografia abdominal não revelou anormalidades de vias biliares.

Foi realizada biópsia hepática em setembro de 2000 , tendo como achado hepatite aguda colestática sem etiologia definida. Foi iniciado teste terapêutico com ácido ursodesoxicólico (Ursacol ${ }^{\circledR}$ ). Em novembro de 2000 apresentava-se com melhora clínica e bioquímica, sendo suspensa a medicação. Em janeiro de 2001 voltou a apresentar novo surto ictérico, tendo nova recidiva em maio do mesmo ano. Foi submetida a nova biópsia hepática, com hepatite crônica de atividade moderada, discreta colestase em zona 3 acinar (alteração estrutural 3/inflamação portal 2/necrose em saca-bocado 3 /atividade do parênquima 2). Foi iniciado tratamento com prednisona ( $20 \mathrm{mg} /$ dia) e azatioprina $(75 \mathrm{mg} / \mathrm{dia})$. Após dois meses foram realizados ajustes de doses dos imunossupressores e reintroduzido o Ursacol ${ }^{\circledR}$. Nas consultas posteriores a paciente apresentou-se bem, sem atividade de doença.

\section{Caso 3}

Paciente do sexo masculino, 84 anos, com queixa de náuseas, inapetência, colúria por 15 dias. Dois meses antes havia apresentado febre, mal-estar, exantema e hipotensão, tendo tido diagnóstico presumptivo de dengue. Ausência de surtos ictéricos no ambiente familiar, sem viagens re-

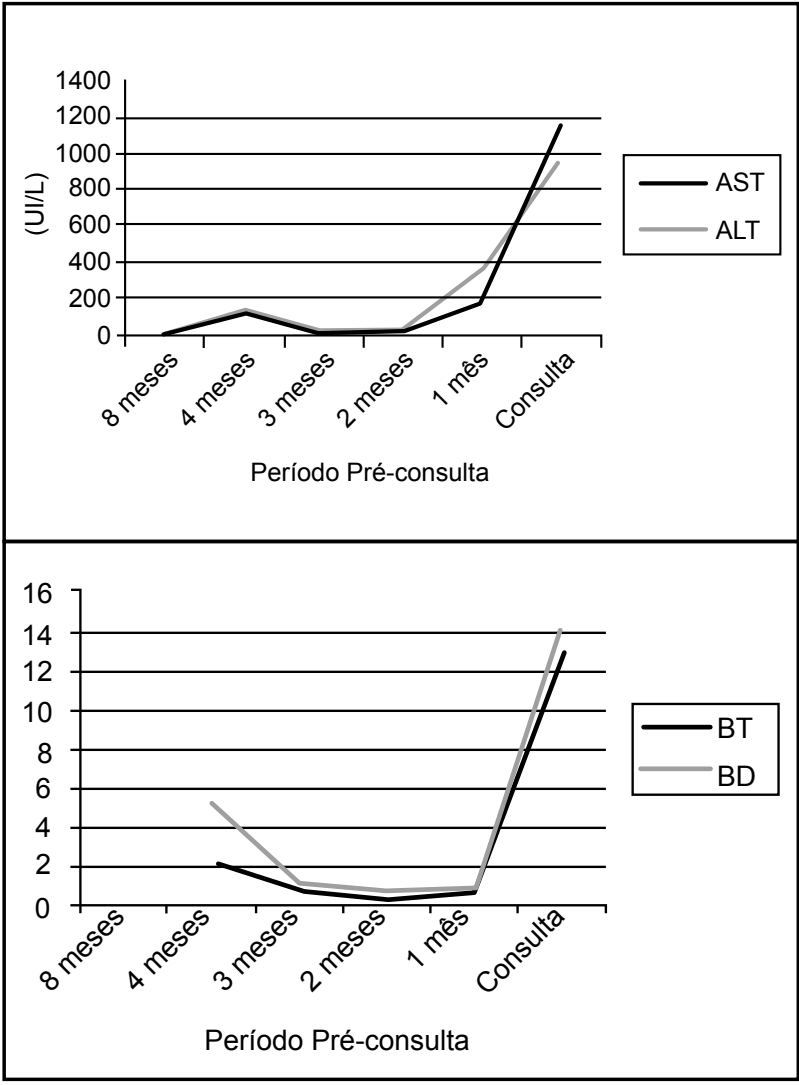

Figuras 4 e 5 - Resultados laboratoriais do caso \#2 - exames anteriores ao acompanhamento

centes. Ao exame apresentava-se ictérico, sem estigmas de hepatopatia crônica. A avaliação laboratorial revelava: AST 307UI/I (valor normal [VN] < 36UI/I); ALT 458UI/I (VN < $52 \mathrm{UI} / \mathrm{l})$; fosfatase alcalina $72 \mathrm{UI} / \mathrm{I}(\mathrm{VN}<126 \mathrm{UI} / \mathrm{l})$; gama-glutamiltransferase (gama GT) 169UI/I (VN < 43UI/l); albumina $4 \mathrm{mg} / \mathrm{dl}$; globulina 2,2mg/dl; TP 75\%; ferritina 2.320ng/ml; saturação de transferrina $90 \%$; ferro $225 \mathrm{mcg} / \mathrm{dl}$; bilirrubina total $3 \mathrm{mg} / \mathrm{dl}$; bilirrubina direta $1,8 \mathrm{mg} / \mathrm{dl}$. Inicialmente suspeitou-se de hemocromatose.

Um mês depois foi realizada laparoscopia exploradora, a qual revelou fígado de volume normal, borda romba e superfície irregular. A biópsia hepática revelou hepatite aguda do tipo viral com necrose submaciça em fase de regressão. O paciente apresentou: anti-VHA-lgG positivo; anti-HBs positivo; IgM-EBV e CMV negativos; anti-VHC e anti-VHE negativo. A pesquisa de auto-anticorpos (antimitocôndria, anti-LKM, anticorpo antinúcleo e antimúsculo liso) foi negativa. Suspeitou-se de hepatite aguda viral por vírus desconhecido em paciente com traço genético para hemocromatose, sendo solicitada a investigação para o vírus $\mathrm{G}$, que foi negativa (RNA-VHG). O paciente evoluiu com melhora clínica espontânea e completa normalização das dosagens de enzimas hepáticas. 


\section{Caso 4}

Paciente do sexo masculino, 34 anos, sem formas de exposição parenteral, fazia uso esporádico de bebidas alcoólicas ( $<25 \mathrm{~g} / \mathrm{dia})$, sem uso de medicamentos, fitoterápicos ou chás. Em setembro de 2004 começou a apresentar fadiga, febre, icterícia e prurido. Fez os seguintes exames: AST $328 \mathrm{UI} / \mathrm{l}(\mathrm{VN}<40 \mathrm{UI} / \mathrm{l})$, ALT 907UI/I $(\mathrm{VN}<40 \mathrm{UI} / \mathrm{l})$, albumina $3,5 \mathrm{mg} / \mathrm{dl}, \mathrm{TP} 100 \%$, fosfatase alcalina $116 \mathrm{U} / \mathrm{I}(\mathrm{VN}<86 \mathrm{UI} / \mathrm{l})$, gama GT 388U/I (VN < 43UI/l). Perfil lipídico, glicemia e ultra-sonografia abdominal sem alterações. Ao exame, índice de massa corpórea (IMC) de $26 \mathrm{~kg} / \mathrm{m}^{2}$, sem outras alterações. Sorologias virais (IgM-VHA, AgHBs, lgM e lgG anti-HBC, antiVHC, anti-VHE, IgM anti-CMV), FAN e anti-LKM negativos, com antimúsculo liso positivo (1/40). Perfil metabólico de ferro, cobre e dosagem de alfa-1-antitripsina normais. O paciente evoluiu com remissão dos sintomas, mas persistência das alterações enzimáticas, com elevação de ALT (acima de oito vezes o limite da normalidade). Novos exames virológicos foram realizados, incluindo VHC-RNA e DNA-VHB, todos negativos. Auto-anticorpos foram repetidos, sendo negativos, com desaparecimento do antimúsculo-liso. Diante da ausência de diagnóstico e da persistência de alterações laboratoriais, o paciente foi submetido a biópsia hepática em março de 2005 (Figuras 6 e 7). O exame revelou arquitetura hepática preservada, infiltração inflamatória mononuclear moderada em espaços porta, presença de múltiplos focos de necrose com infiltrado inflamatório mononuclear no parênquima, células de Kupffer e macrófagos fagocitando material PAS diastase-resistente, moderada sobrecarga de ferro e ausência de fibrose. O patologista concluiu que os achados eram sugestivos de hepatite aguda do tipo viral prolongada. O paciente manteve acompanhamento, sem normalização do perfil bioquímico. Diante disso, optou-se por realizar um teste terapêutico com prednisona $(40 \mathrm{mg} / \mathrm{d})$, não havendo, porém, melhora bioquímica, sendo suspensa a medicação.

\section{Discussão}

Nosso grupo relatou neste estudo quatro casos de hepatite aguda criptogênica, com quadros clínicos variáveis e possibilidade de complicações, justificando criteriosa investigação e seguimento desses pacientes.

A hepatite é considerada criptogênica apenas após uma extensa avaliação ter excluído fatores etiológicos conhecidos: álcool, vírus, doenças auto-imunes, doenças metabólicas e medicamentos. Cerca de $5 \%$ a $30 \%$ das

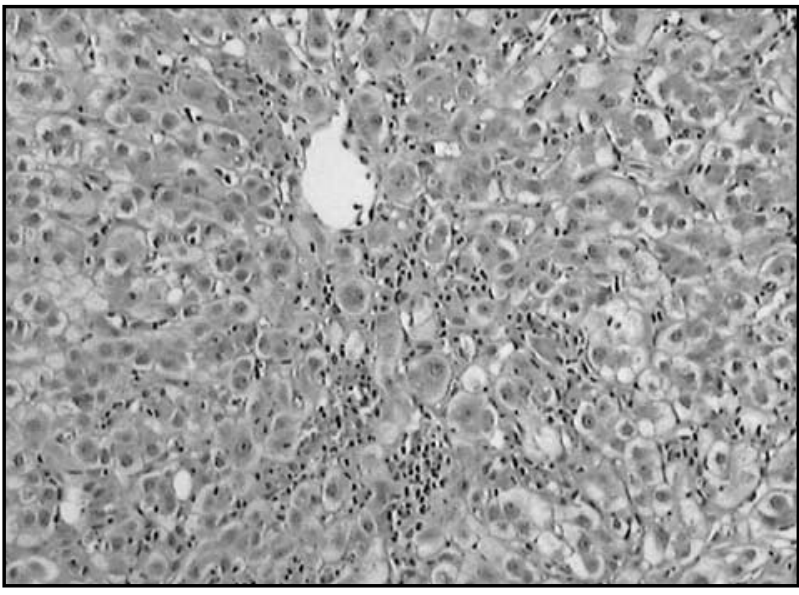

Figura 6 - Zona central do ácino mostrando leucócitos mononucleares enfileirados na região peri-sinusoidal e sinusoidal ( $H \& E, 200 X)$

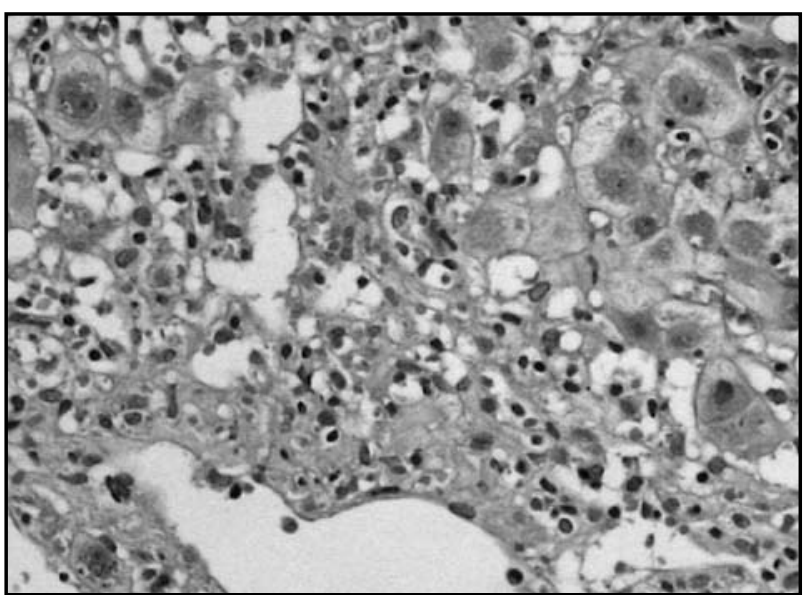

Figura 7 - Zona central com dilatação da veia, peri-flebite, circundada por hepatócitos que exibem balonização (H\&E, 200X)

hepatites agudas permanecem com causa não-determinada. Aproximadamente um terço das hepatites fulminantes tem causas desconhecidas, $13 \%$ das pós-transfusionais nos Estados Unidos são inexplicadas e a prevalência da cirrose criptogênica varia de $5 \%$ a $30 \%{ }^{(1)}$.

As manifestações das hepatites de origem indefinida são variadas. O quadro pode ser compatível com insuficiência hepática grave com coagulopatia e encefalopatia ou simplesmente o paciente é assintomático e apresenta elevação persistente de enzimas hepáticas. Por outro lado, o indivíduo pode apresentar-se com complicações relacionadas à hipertensão portal e com sinais de descompensação de uma doença hepática crônica sem causa definida.

O padrão-ouro para investigação diagnóstica e para estadiamento de uma doença hepática é a biópsia hepática. Possíveis explicações para hepatites crônicas ou cirrose criptogênicas incluem consumo alcoólico oculto, hepatites virais não-B e não-C, hepatite auto-imune atípica, NASH, 
deficiência de alfa-1-antitripsina, doença de Wilson, hepatite medicamentosa.

O papel da biópsia hepática no diagnóstico e no estadiamento da hepatite aguda não está definido. Evidentemente, a biópsia pode ajudar na exclusão de possíveis etiologias, mormente aquelas de natureza tóxica ou auto-imune. Por outro lado, pouco se conhece a respeito dos aspectos histopatológicos das hepatites criptogênicas agudas e crônicas. Assim, o estudo histopatológico não poderia ser tomado como fator de definição diagnóstica ${ }^{(10)}$. Portanto, a biópsia hepática deve ser indicada àqueles pacientes que cursam com evidências de agressão hepatocelular persistente após seis meses de acompanhamento, podendo também ser considerada em fase aguda diante da ausência de diagnóstico etiológico.

Recentemente, Skelly et al. ${ }^{(12)}$ descreveram os achados de biópsias hepáticas em 354 pacientes com elevações inexplicadas de enzimas hepáticas. Um total de $6 \%$ dos pacientes tinha biópsias normais, $26 \%$ apresentavam algum grau de fibrose e $6 \%$ eram cirróticos; $34 \%$ das biópsias eram sugestivas de NASH. Outros diagnósticos incluíam hepatite criptogênica (9\%), hepatotoxicidade $(7,6 \%)$, doença alcoólica do fígado $(2,8 \%)$, hepatite auto-imune $(1,9 \%)$, cirrose biliar primária $(1,4 \%)$ e colangite esclerosante primária $(1,1 \%)$. Nessa coorte, o manejo do paciente foi diretamente modificado, de acordo com o exame patológico, em $18 \%$ dos casos, e três famílias entraram em programa de screening para doenças hereditárias. Esses resultados sugerem que, na ausência de contra-indicações, a biópsia hepática deve ser realizada em pacientes com anormalidades persistentes e inexplicadas de enzimas hepáticas. Já na doença aguda, a escassez de estudos impede definir o papel da biópsia hepática no diagnóstico e no prognóstico dessa condição.

Uma proporção significativa de pacientes com hepatite auto-imune se apresenta, inicialmente, com quadro clínico sugestivo de hepatite aguda viral e ao longo da evolução vão apresentando sinais típicos de auto-imunidade. Inversamente, alguns pacientes com hepatites agudas virais apresentam auto-anticorpos positivos em baixos títulos, que desaparecem ao longo do seguimento, sem maiores implicações ${ }^{(3)}$. Assim, os achados histológicos podem ser de fundamental importância no sentido de direcionar as suspeitas diagnósticas e as condutas a serem adotadas, principalmente diante de achados histológicos sugestivos de auto-imunidade em paciente do sexo feminino.

Em dois dos casos apresentados, ambos femininos, alguns dados eram sugestivos de hepatite auto-imune (sexo feminino, sorologias virais persistentemente negativas, presença de hepatite de interface), embora as pacientes apresentassem globulinas normais, auto-anticorpos negativos ou positivos transitoriamente em baixos títulos, ausência de outras doenças auto-imunes. Nesses casos, a pesquisa de perinuclear anti-neutrophil cytoplasm (P-ANCA) não foi realizada, nem a de antígenos de histocompatibilidade HLADR3 ou DR4. De qualquer forma, houve alguma resposta à imunossupressão, o que sugeriu a possibilidade de hepatite auto-imune atípica nesses pacientes. Assim, a resposta ao tratamento com corticóide pode ser um argumento suplementar para o diagnóstico de hepatite auto-imune. Será necessário avaliar posteriormente o papel do teste terapêutico com imunossupressão nestes pacientes.

Pacientes que tenham o diagnóstico provável de hepatite auto-imune (variante seronegativa) podem ser candidatos à terapia imunossupressora com corticóides desde que não tenham contra-indicações ao tratamento e apresentem alguns critérios: sexo feminino, hipergamaglobulinemia, outras doenças auto-imunes (doenças tiroidianas, acidose tubular renal, anemia perniciosa), presença de human leukocyte antigen (HLA-B8), HLA-DR3 ou DR4, ausência de marcadores virológicos e achados histológicos sugestivos de doença progressiva ${ }^{(4)}$.

Poucos estudos avaliaram o tratamento e o prognóstico das hepatites criptogênicas. Um deles sugeriu que os pacientes com hepatite crônica criptogênica respondem aos corticóides de maneira semelhante àqueles com hepatite auto-imune e com índices de remissão e resposta sustentada semelhantes entre os dois grupos ${ }^{(4)}$. Não existe um consenso sobre o esquema terapêutico a ser introduzido nesses casos, sendo fundamental um seguimento cauteloso desses pacientes.

No terceiro caso clínico descrito, o paciente apresentou sinais prodrômicos antes do surgimento da icterícia, além de elevação de ALT acima de dez vezes o limite normal, com evolução benigna marcada por resolução espontânea da agressão hepatocelular, o que argumenta a favor de uma etiologia viral na ausência de outros possíveis fatores, como uso de medicações. Recentemente, vários vírus foram investigados no contexto de hepatites crônicas desconhecidas, como os vírus $G$, TTV e SEN-V, mas o papel etiológico desses agentes não ficou documentado ${ }^{(5,8,13)}$. Alguns autores sugerem a importância da infecção oculta pelo vírus $B$, embora seu papel etiológico nas hepatites criptogênicas seja ainda controverso(2). Nesse caso, infecções B e C ocultas foram afastadas por testes biomoleculares sensíveis.

É importante destacar a possibilidade de evolução desfavorável com o aparecimento precoce de fibrose hepática 
extensa, como foi visto no caso 1. Em relação a esse caso, não foram identificados fatores etiológicos para a esteatose, já que a paciente não fazia uso de álcool ou outras drogas, nem apresentava sinais de síndrome metabólica (ausência de diabetes, hipertensão arterial, sobrepeso ou dislipidemia). Esteatose hepática é também observada com freqüência em pacientes com hepatite $C$, mormente naqueles portadores do genótipo 3 . Nesses casos, a infiltração gordurosa não está associada a sobrepeso ou síndrome plurimetabólica, fato que sugere citotoxicidade da cepa viral no hepatócito( ${ }^{(6)}$. Assim, a presença de esteatose nesse caso não permite afastar uma etiologia viral.

A possibilidade de doença evolutiva justifica manter 0 acompanhamento de pacientes com alteração persistente de enzimas hepáticas. Apesar do aspecto histológico inocente visto em alguns casos criptogênicos, o potencial evolutivo é atestado pela presença de fibrose numa porcentagem nãodesprezível de casos. Isso reforça a importância do seguimento dos casos criptogênicos mesmo que, num primeiro instante, encontrem-se anormalidades histológicas mínimas.
Em conclusão, apesar dos avanços no campo diagnóstico, sobretudo na área da biologia molecular, uma proporção substancial de pacientes continua a apresentar doenças hepáticas de etiologia ainda não-esclarecida. Isso justifica a realização de novos estudos clínicos, histológicos e epidemiológicos. Nas pacientes do sexo feminino, a hepatite auto-imune atípica deve ser fortemente suspeitada, contudo, nos pacientes do sexo masculino, esta possibilidade é menos evidente. As hepatites criptogênicas compreendem um grupo heterogêneo de doença. Diante da possibilidade de evolução prolongada com complicações, tornam-se imperativos o seguimento desses casos e a investigação de possíveis mecanismos etiológicos: infecção viral oculta, doença auto-imune ou metabólica. Estudar a natureza do infiltrado inflamatório nas hepatites criptogênicas pode ser importante para definir a patogênese da agressão hepática nesses pacientes, contribuindo para o melhor entendimento etiológico desse processo, ou seja, a diferenciação entre um processo de origem viral, autoimune ou metabólico.

\section{Referências}

I. CALDWELL, S. H. et al. Cryptogenic cirrhosis: clinical characterization and risk factors for underlying disease. Hepatology, v. 48, n. 3, p. 664-9, 1999

2. CHEMIN, l. et al. High incidence of cryptic hepatitis b infection among chronic hepatitis cases of unknown etiology.J Hepatol, v. 34, n. 3, p. 447-54, 2001

3. CODES, L. et al. Frequency and implications of autoantibodies in acute viral hepatitis. Rev Soc Bras Med Trop, v. 35, n. 5, p. 465-9, 2002

4. CZAJA,A. J. et al.The nature and prognosis of severe cryptogenic chronic active hepatitis. Gastroenterology, v. 104, n. 6, p. |755-6|, 1993.

5. HAYASHI, K. et al.TT virus (TTV) infection in patients with acute hepatitis. Nippon Rinsho, v. 57, n. 6, p. 1322-5, 1999.

6. HEZODE, C. et al. Different mechanisms of steatosis in hepatitis $C$ virus genotypes I and 3 infections. J Viral Hepat, v. I I, n. 5, p. 455-8, 2004.

7.JOHNSON, P..:; McFARLANE, I. G. Meeting Report: International Autoimmune Hepatits Group. Hepatology, v. 18, p. 998, 1993
8. NAKANO, l. et al.TT virus (TTV) is not associated with acute sporadic hepatitis. Fukuda Y Infection, v. 27, n. 2, p. 125-7, 1999

9. PARANA, R. et al. Clinical, histological and serologic evaluation of patients with acute non A-E hepatitis in North-Eastern Brazil: is it an infectious disease? Int J Infect Dis, v. 7, n. 3, p. 220-30, 2003.

10. PARANA, R. et al. Acute sporadic non-A, non-B hepatitis in North-eastern Brazil: etiology and natural history. Hepatology, v. 30, n. I, p. 289-93, 1999.

I I.POONAWALA, A.; NAIR, S. P.; THUBUVATH, P. J. Prevalence of obesity and diabetes in patients with cryptogenic cirrhosis: a case-control study. Hepatology, v. 32, n. 4, p. 689-92, 2000.

12. SKELLY, M. M.; JAMES, P. D.; RYDER, S. D. Findings on liver biopsy to investigate abnormal liver function tests in the absence of diagnostic serology. Journal of Hepatology, v. 35 , p. 195-9, 2001.

I 3.YOSHIDA, H. et al.WeakAssociation Between SENVirus Viremia and Liver Disease. Journal of Clinical Microbiology, v. 40, n. 9 p. $3 \mid 40-5,2002$ 